\title{
Order-picking in deep cold - physiological responses of younger and older females. Part 2: body core temperature and skin surface temperature
}

\author{
Sandra Baldus ${ }^{*}$, Karsten Kluth and Helmut Strasser \\ Ergonomics Division, University of Siegen, Paul-Bonatz-Str. 9-11, D-57068 Siegen, Germany
}

\begin{abstract}
So far, it was unclear to what extent working in deep cold-storage depots has an influence on female order-pickers body core temperature and skin surface temperature considering different age groups. Physiological effects of order-picking in a chill room $\left(+3^{\circ} \mathrm{C}\right)$ and cold store $\left(-24^{\circ} \mathrm{C}\right)$ were examined on 30 female subjects $(\mathrm{Ss})$, classified in two age groups (20- to $35-$ year-olds and 40- to 65-year-olds). The body core temperature was taken every $15 \mathrm{~min}$ at the tympanum and the skin surface temperature was recorded continuously at seven different positions. Working in the chill room induced a decrease of the body core temperature up to $0.5 \mathrm{~K}$ in comparison to the value at the outset for both age groups which could be compensated by all Ss during the breaks. Working in the cold store caused a decline up to $1.1 \mathrm{~K}$ for the younger Ss and $1.3 \mathrm{~K}$ for the older Ss. A complete warming-up during the breaks was often not possible. Regarding the skin surface temperature, working in the chill room can be considered as unproblematic, whereas significantly lower temperatures at nose, fingers and toes, associated with substantial negative subjective sensations, were recorded while working in the cold store.
\end{abstract}

Keywords: Field Study, Manual Material Handling, Age, Physiology, Severe Environmental Conditions

\section{Introduction}

Today's food supply system is built up to a great extent on refrigeration technology. In line with the trend of recent years, it is reasonable to assume that chilled and frozen food will experience a growing significance in the future. Due to this trend, the number of workplaces in cold-storage depots is also likely to increase in the future. As a cold environment may be a significant health risk factor (cp. $[13,39])$, work organisation as well as technical and constructional equipment in cold-storage depots should be designed on the basis of ergonomic measurements. Kluth et al. [19,20] noted that design changes within a cold-storage depot with chill room and cold store are feasible only to a minor extent due to management requirements and operational equipment. Thus, a sufficient number of scientific study results (cp. [19,20,29,38]) show, that improvements related to workplaces in deep cold should focus on cold-protective clothing as well as duration and frequency of the warming-up breaks.

Order-picking in a cold storage depot and the associated deviation from the comfortable thermic zone may result in decreased physical (cp. [27]) and mental performance (cp. [30]). Physical performance, defined by Oksa et al. [28] and Faulkner et al. [9], is a combination of endurance, muscular fitness and physical skills. The cooling of the muscles affects the physical performance which then impairs most of its functional properties like power, force and velocity. The mental performance, which according to Pilcher et al. [31], plays an important role in the areas of orientation, safety, decision-making, work productivity and reactions to emergency situations is also influenced by a cold environment. According to a survey

*Corresponding author. E-mail: baldus@ergonomie.uni-siegen.de 
commissioned by Ramsey et al. [33], the ambient temperature has a statistically significant effect on the unsafe behaviour index (UBI). This is expressed through a U-shaped curve, with minimum UBI values occurring in the preferred temperature zone of $17^{\circ} \mathrm{C}$ to $23^{\circ} \mathrm{C}$ and an increase in the UBI for hot and cold environments. In addition to the negative impacts on the physical and mental performance, working in a cold storage depot can also have an impact on an individual's health. As stated by Oksa et al. [28] and Sormunen et al. [35], while working in these conditions, an increased muscular strain and other musculoskeletal complaints and symptoms are common. Mäkinen [22] further reported that everyday cold exposure may aggravate the symptoms of prevailing chronic diseases. Hassi et al. [14] mentioned that many types of chronic health problems such as cardiovascular diseases, respiratory symptoms, musculoskeletal diseases, peripheral circulation problems, and skin diseases, are associated with cold exposure. The heat loss, which may cause the complaints described, cannot completely be compensated by protective clothing and peripheral vasoconstriction (cp. [38]). Therefore, an increased energy expenditure is required, with the result that, due to its "heating effect", the physical strenuous work of manually handling of deep-frozen groceries is beneficial and necessary rather than disadvantageous (cp. $[19,20]$ ). According to Boothby et al. [5] increasing age is associated with a decrease of the physical capacity and the energy metabolism which leads to a poorer protection against cold. Two parameters which were utilised to monitor the comfortable thermic zone are the body core temperature and the skin surface temperature.

Work stress, surrounding temperature, time of day and in the case of female workers the menstrual cycle are the primary factors responsible for body core temperature changes. Work stress affects the core temperature - generally taken rectally - greater than the surrounding temperature. For work stress, the rectal temperature increases linearly with oxygen intake, whereby an increase of the oxygen intake by 1 liter (that is somewhat above the endurance level) also increases the rectal temperature by about $0.5 \mathrm{~K}$ to $0.8 \mathrm{~K}$ (cp. e.g. $[2,25,34]$ ). Time of day causes a body core temperature variation of about $1{ }^{\circ} \mathrm{C}$, while the female's menstrual cycle causes a variation of approximately $0.5^{\circ} \mathrm{C}$. When it comes to core temperature changes during exposure to the cold the results of different studies vary widely. Hellstrøm et al. [15] registered a decrease of $0.5 \mathrm{~K}$ after an one-hour exposure to the cold, when reducing the surrounding temperature from $10^{\circ} \mathrm{C}$ to $0^{\circ} \mathrm{C}$. In contrast, Forsthoff [10] detected an increase of up to $1.0 \mathrm{~K}$ compared to the value of the outset, after 50 minutes order-picking at $-28^{\circ} \mathrm{C}$ surrounding temperature. Kleinöder [17] confirmed these results in laboratory tests simulating activities at $-28^{\circ} \mathrm{C}$. Kluth et al. $[19,20]$, however, executed whole working-day tests in a cold store (at $24^{\circ} \mathrm{C}$ ) with professional and non-professional male subjects. After two hours of order-picking the core temperature decreased up to $1.5 \mathrm{~K}$ (younger subjects) and $2.2 \mathrm{~K}$ (older subjects). Even if research findings so far indicate that an increase of the work performance and/or a sufficiently adapted increase of the warming insulation of the cold-protective clothes compensates for the substantial drops of the core temperature (cp. $[4,10,40])$, the results of Kluth et al. $[19,20]$ demonstrate that this is possible only to a limited extent. One subject of the test series exhibited a resulting core temperature of approximately $34^{\circ} \mathrm{C}$ which, according to a German standard [44], approaches a value that poses a risk to health (cp. [20]). This German standard indicates that the core temperature can drop to $35^{\circ} \mathrm{C}$ without any health risk, but any further cooling down would be lifethreatening.

The temperature variations in the peripheral tissues (body's outer structure) are greater than in the body core when changing the surrounding temperature. The reason for this is a strong decrease of the blood circulation in the skin during exposure to the cold. The result is an isolating shell of variable thickness, caused by radial and axial gradients formed in the peripheral layers. At low surrounding temperatures the shell is going to be thicker which causes a temperature drop at first only in the body periphery. In particular, the temperatures at the ends of the extremities change greatly with the surrounding temperature (cp. $[1,18])$.

The local cooling of the surface, especially of hands, feet and head may cause physical discomfort, a deterioration of the manual and physical capacity and cold injuries (cp. [43]). According to an international standard [42], the skin surface temperature is influenced by the heat exchange (consisting of convection, radiation and evaporation) as well as fluctuations of the skin blood circulation and temperature changes of the arterial blood which reaches the respective body part. The latter factor greatly depends of the entire heat balance, which is negative, if the protective clothing does not meet the IREQ (required clothing insulation). Experiments carried out in laboratories (cp. $[6,12,17,24,26])$ showed that the skin of hands, feet and face are most affected by cold exposure. Gavhed et al. [12] showed that an air tempera- 
ture of $-10^{\circ} \mathrm{C}$ (with wind speed of $0.2 \mathrm{~m} / \mathrm{s}$ ) led to a decrease of the nose temperature down to $10^{\circ} \mathrm{C}$ even when walking on a treadmill at $2.8 \mathrm{~km} / \mathrm{h}$. It should further be noted that the skin temperature of the nose decreased when the wind speed increased and also that higher exercise intensity (by increasing the incline of the treadmill) had a positive effect on the skin temperature. A field study, carried out by Forsthoff [10], which was already mentioned above, exhibits that the toes are also affected to a great extent when working in extreme cold conditions. Forsthoff registered a decrease of the toes skin temperature up to $16 \mathrm{~K}$ compared to the value of the outset which could not completely compensated during the warming-up breaks. While the skin temperatures of the torso could be influenced by variation of energy expenditure and thickness of the clothing, the temperatures of feet and toes could only be influenced by an improved protection against the cold through an increased insulation of the boots (cp. [10]). The above mentioned whole-working day tests, carried out by Kluth et al. [19,20], recorded an average skin surface temperature decrease of the nose down to $+15^{\circ} \mathrm{C}$ during 2 hours exposure to the cold. The temperature decrease of the toes was smaller but continuous. While the nose and the fingers warmed up completely during the breaks, the toes only completely warmed up within a minimum of 20 minute warming-up break, and if the boots were taken off. Skin temperature sensors under the thick protective clothing (installed in the area of the kidney and shoulder) registered no substantial temperature changes. When comparing the results from Kluth et al. $[19,20]$ with the results from Forsthoff [10] it can be concluded that only widely successful protective clothes can compensate for the potential negative health effects of working in deep cold.

\section{Methods}

Fifteen female subjects (Ss), each, in two age groups (20- to 35- and 40- to 65-year-olds; cp. Table 1) were asked to carry out whole-working day tests in order to assess whether order-picking in a cold-storage depot with chill room (approx. $+3^{\circ} \mathrm{C}$ ) and cold store (approx. $-24^{\circ} \mathrm{C}$ ) is sustainable at any age for female workers in the long run. The Ss had to work under predetermined, realistic working conditions in a chill room and in a cold store with modified working phases with a duration of 80,100 , and 120 minutes,
The studies from Gavhed et al. [12] also suggest that increased energy expenditure can have a positive effect on the skin surface temperature. Therefore, the physical strain of order-pickers can also be seen as advantageous in the context of successful protection against cold regarding the skin temperatures, which is confirmed by studies of Imamura [16]. A decline of the skin surface temperature, especially in the hands and feet can lead to a loss of mobility, sensitivity and agility (cp. [41]). Referring to Fox [11] and Provins and Clarke [32] the temperature of the hands is clearly a limiting factor in the performance of manual tasks in the cold. Morton and Provins [23] and Stevens et al. [36] defined $8-10^{\circ} \mathrm{C}$ as a critical hand and finger skin temperature for unimpaired tactile sensitivity, and $12-15^{\circ} \mathrm{C}$ was defined as critical temperature for manual dexterity by Clark [7] and Dusek [8]. Besides the restriction in the performance of manual tasks, health problems like ankylosis can be the outcome of recurring exposures to the cold with low skin temperatures (cp. [3]). In order to create sustainable jobs which do not pose a substantial threat to health, it is necessary to optimize the cold protective clothing in combination with an appropriate combination of work time and warming-up breaks. Optimization however must be achieved in consideration of the features of the individual, as the factors that affect thermal responses are age, gender, fitness, health, pre-existing diseases and medication (cp. [37]). Nevertheless, Kluth et al. [19,20] made an important contribution to the age-differentiated assessment of the effects of working in the cold, but until now limited to male subjects. However, the female body has some different characteristics which create quite different conditions regarding working in the cold.

separated by identical warming-up breaks of $20 \mathrm{~min}$ utes, each, at about $+21^{\circ} \mathrm{C}$. To achieve results that can be compared, the Ss had a work load adapted to the real job with an average of 1.6 tons $(t)$ of goods to be order-picked within one hour (8t per day). During the whole working day, the body core temperature was taken at the tympanum every 15 minutes and the skin surface temperature was monitored continuously at 7 positions (cp. Figure 1).

In addition, parameters of the blood circulation (heart rate and blood pressure) and the energy metabolism were measured (cp. [21]).

During performing the tasks, the Ss had to wear cold-protective clothing (equal to the clothes worn by the professional female order-pickers). Adapted to the surrounding temperatures, in the chill room, 
warm underwear, a pair of trousers, a thermo shirt, a thermo vest, a wool hat, knitted gloves and thermoinsulated shoes were used. In the cold store, the Ss were equipped with a cold-protective suit consisting of a thick jacket and long trousers which they had to wear above their underwear, pullover and pair of trousers. Further protection against the cold was provided by thermo socks, fleece gloves, a wool hat and cold-insulating boots.

Table 1

Characteristics of the female subjects, 15 each in the age group "young" (left part) and "old" (right part)

\begin{tabular}{|c|c|c|c|c|c|c|c|}
\hline Ss "young" & Age [Years] & Height [m] & Weight [kg] & Ss "old" & Age [Years] & Height [m] & Weight [kg] \\
\hline 01 & 27 & 1.74 & 73 & 01 & 59 & 1.69 & 80 \\
\hline 02 & 24 & 1.76 & 68 & 02 & 54 & 1.63 & 52 \\
\hline 03 & 25 & 1.67 & 67 & 03 & 61 & 1.68 & 61 \\
\hline 04 & 22 & 1.76 & 64 & 04 & 52 & 1.56 & 57 \\
\hline 05 & 20 & 1.62 & 54 & 05 & 53 & 1.70 & 61 \\
\hline 06 & 20 & 1.70 & 77 & 06 & 59 & 1.61 & 53 \\
\hline 07 & 20 & 1.70 & 65 & 07 & 57 & 1.70 & 71 \\
\hline 08 & 21 & 1.80 & 66 & 08 & 43 & 1.58 & 73 \\
\hline 09 & 22 & 1.60 & 59 & 09 & 44 & 1.66 & 67 \\
\hline 10 & 25 & 1.70 & 58 & 10 & 51 & 1.68 & 60 \\
\hline 11 & 28 & 1.63 & 50 & 11 & 44 & 1.76 & 77 \\
\hline 12 & 27 & 1.69 & 59 & 12 & 50 & 1.64 & 60 \\
\hline 13 & 21 & 1.58 & 51 & 13 & 64 & 1.73 & 104 \\
\hline 14 & 32 & 1.71 & 77 & 14 & 61 & 1.73 & 103 \\
\hline 15 & 26 & 1.58 & 71 & 15 & 48 & 1.68 & 55 \\
\hline$\overline{\mathbf{x}} \pm \mathbf{S}_{\mathbf{d}}$ & $24.0 \pm 3.6$ & $1.68 \pm 0.1$ & $63.9 \pm 8.7$ & $\overline{\mathbf{x}} \pm \mathbf{S}_{\mathbf{d}}$ & $53.3 \pm 6.7$ & $1.67 \pm 0.1$ & $68.9 \pm 16.4$ \\
\hline
\end{tabular}
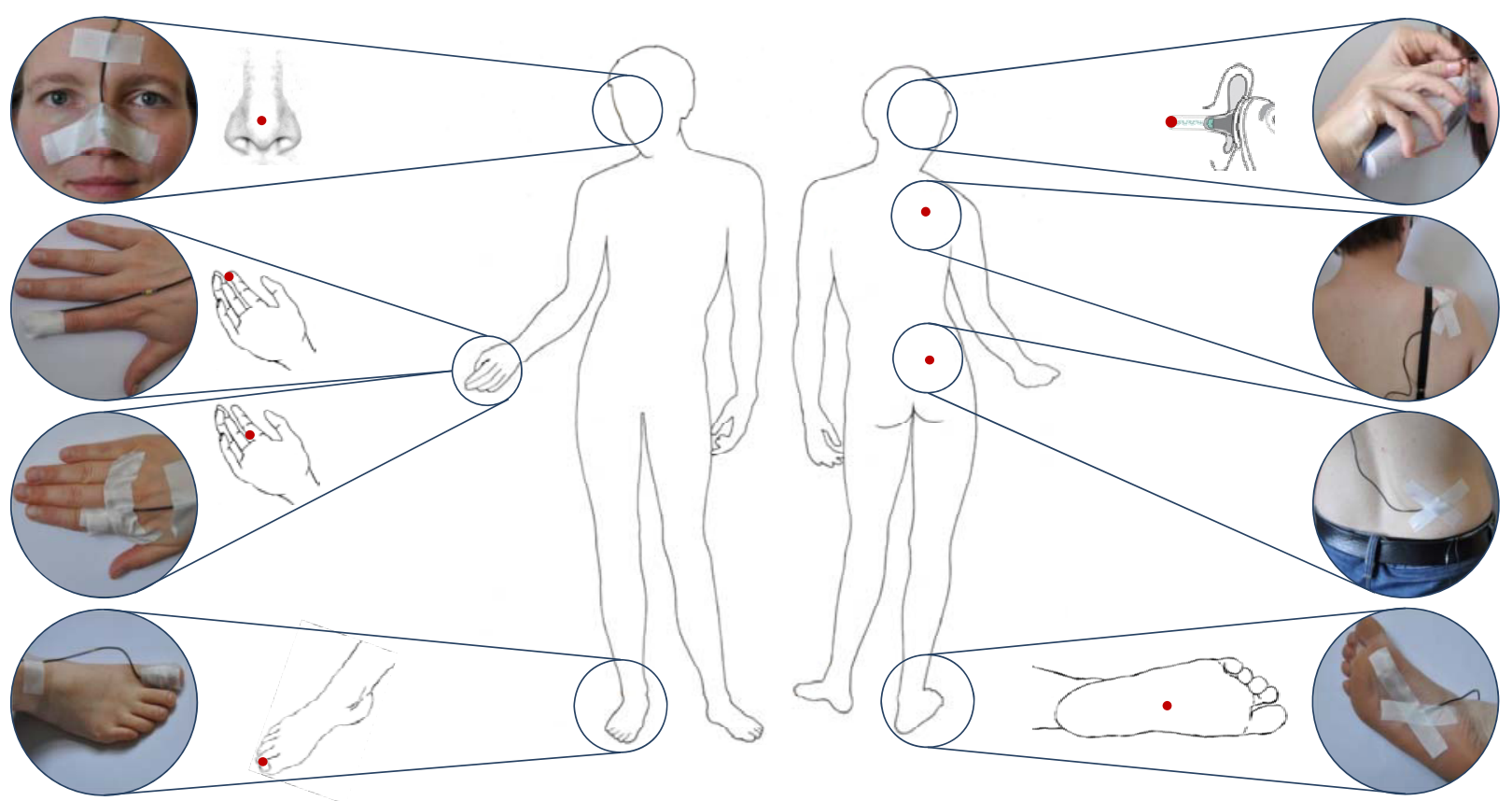

Fig. 1. Measuring points for the recording of the skin temperature (nose and 6 additional measuring points on the right part of the body) and the body core temperature (right ear) 


\section{Results}

As can be seen from Figure 2, while working in the cold store at a surrounding temperature of $-24^{\circ} \mathrm{C}$, the core temperature taken with an ear thermometer at the tympanum every $15 \mathrm{~min}$, differed by $1.1 \mathrm{~K}$ (after the $80 \mathrm{~min}$ exposure to the cold) to $1.3 \mathrm{~K}$ (after the 120 min exposure) in the age group of the 40- to 65year-olds compared to the temperature at the outset $\left(36.9^{\circ} \mathrm{C}\right)$. In the age group of the 20 - to 35 -year-olds (see white columns in Figure 2), after 80 min working in the cold at $-24^{\circ} \mathrm{C}$ the core temperature dropped by $0.9 \mathrm{~K}$ and $1.1 \mathrm{~K}$ after $120 \mathrm{~min}$ working in the cold compared to the temperature at the outset $\left(37.0^{\circ} \mathrm{C}\right)$. In both age groups, the temperature at the outset was often not quite fully reached after a 20 min warmingup phase. While working in the chill room, with a surrounding temperature of about $+3^{\circ} \mathrm{C}$, the decrease of the core temperature was comparatively low. Figure 3 shows a maximum decrease of $0.5 \mathrm{~K}$ from the value of the outset for both age groups in different working phases. Furthermore, the temperature at the outset was mostly reached from the Ss of both agegroups after a 20 min warming-up phase.

Figure 4 visualizes a considerable decrease of the skin temperature at the nose, which was exposed to the cold without any protection. The temperature dropped on average to $15^{\circ} \mathrm{C}$ and $16^{\circ} \mathrm{C}$ for the younger and older $\mathrm{Ss}$, respectively, while working $120 \mathrm{~min}$ in the cold storage depot at $-24^{\circ} \mathrm{C}$. The low temperature of the nose could be compensated very quickly during the warming-up breaks, supported by a more intensive blood circulation of the face after leaving the cold store. The temperature profile of the toe in Figure 4 showed a somewhat smaller but continuous decrease with a significant difference between the absolute average temperatures of both age groups.

The skin temperature of the fingertip (not graphically shown) exhibits a similar trend as the nose with average temperatures of approx. $20^{\circ} \mathrm{C}$ for both age groups. The sensor under the sole of the foot measured nearly constant temperatures throughout the entire working day. As to be expected, the temperature sensors in the area of the shoulder and kidney recorded inconspicuous values. Due to the thick cold protective clothing, the skin surface temperature decreased only slightly, and the value of the outset was reached after a very short time during the warmingup break.

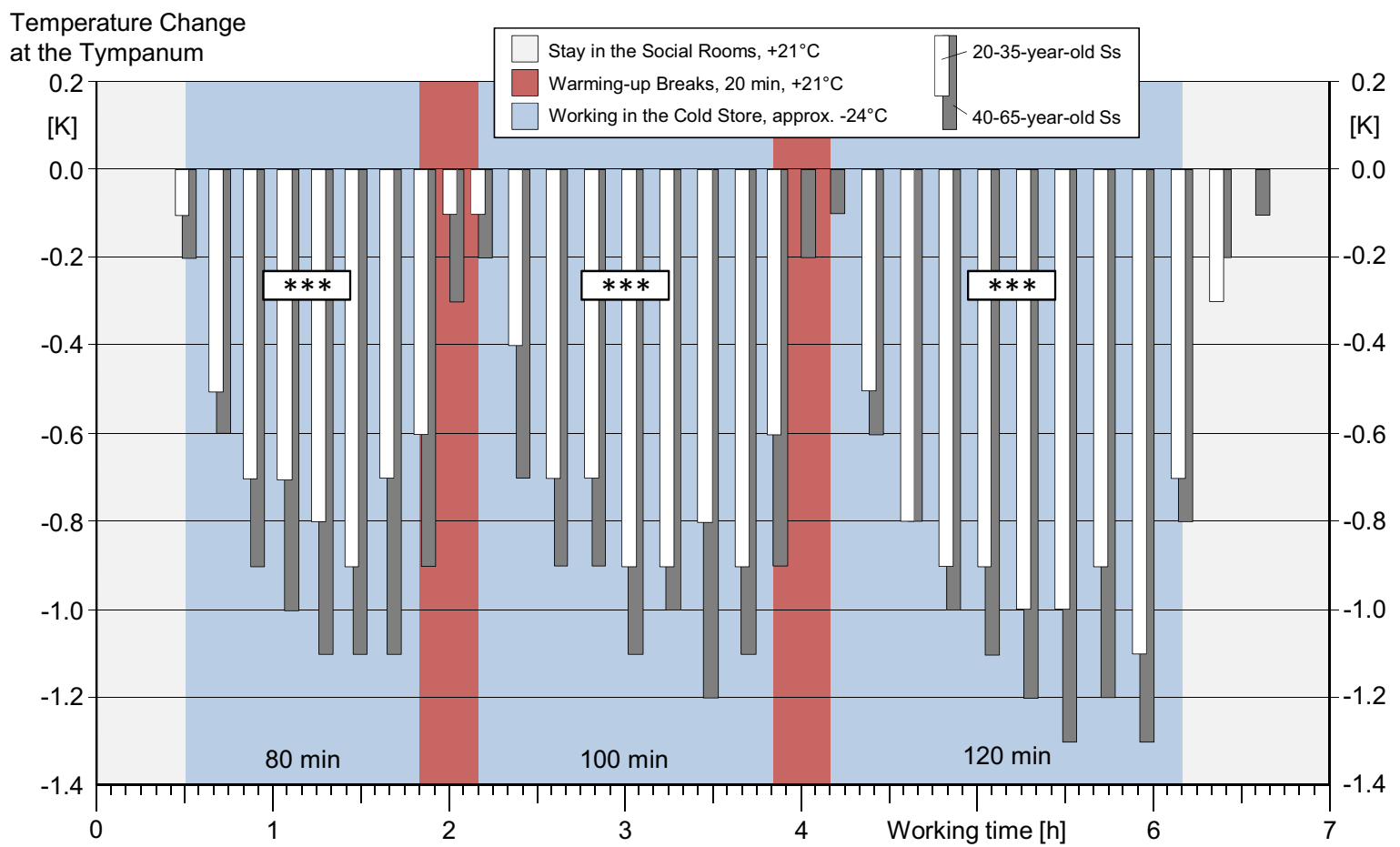

Fig. 2. Tympanum (core) temperature changes [K] of female order-pickers prior to, during and after cold exposures of 80,100 , and 120 min at approx. $-24^{\circ} \mathrm{C}$ in the cold store. Means of $15 \mathrm{Ss}$ in two age groups, each, with symbolic labeling of statistically significant differences of the two-sided t-test (-: $\mathrm{p} \geq 0.05 . *$ : $\left.<<0.05, * *: \mathrm{p}<0.01,{ }^{* * *}: \mathrm{p}<0.001\right)$. 


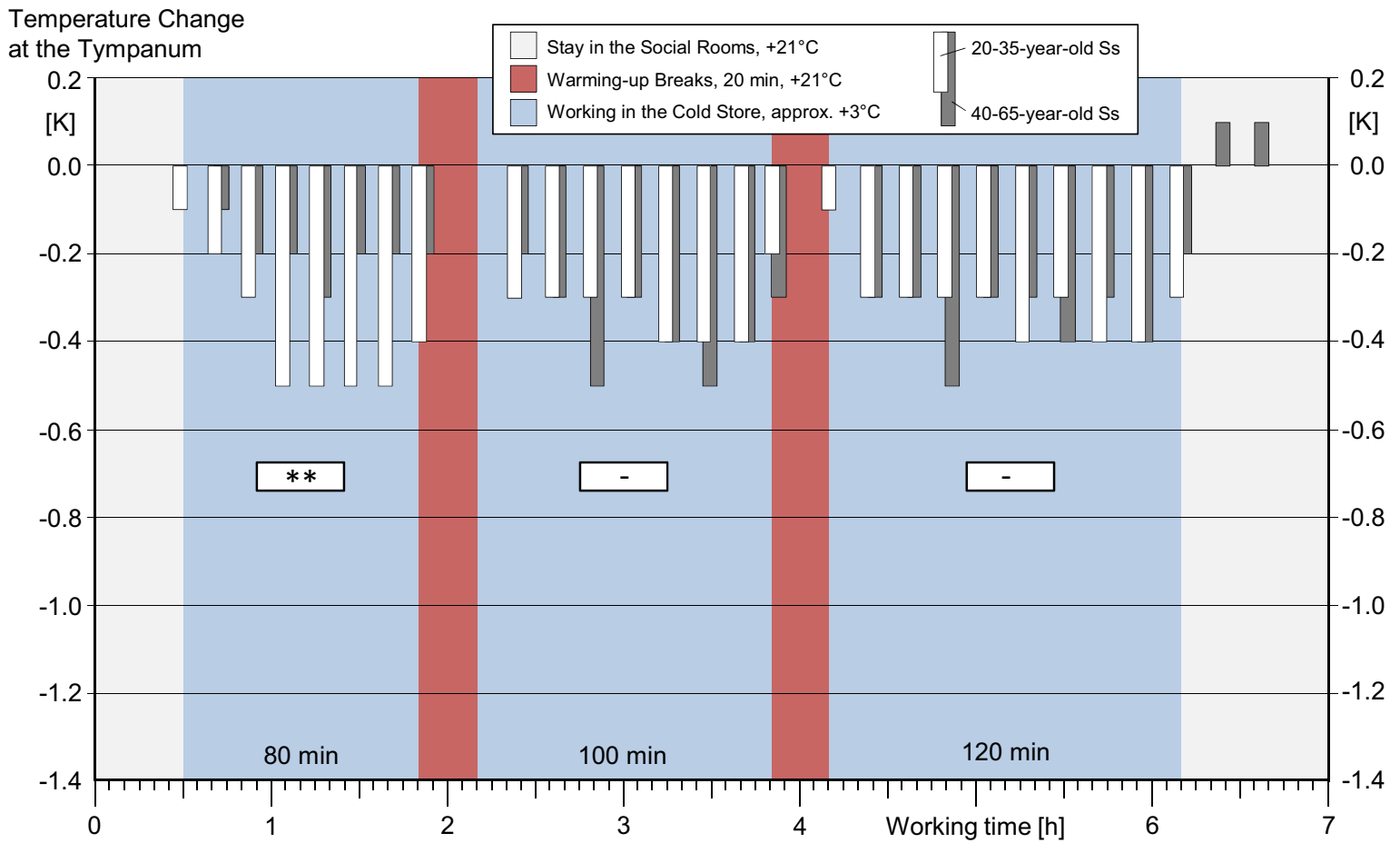

Fig. 3. Tympanum (core) temperature changes [K] of female order-pickers prior to, during and after cold exposures of 80,100 , and 120 min at approx. $+3^{\circ} \mathrm{C}$ in the chill room. Means of $15 \mathrm{Ss}$ in two age groups, each, with symbolic labeling of statistically significant differences of the two-sided t-test $\left(-: \mathrm{p} \geq 0.05\right.$. $\left.^{*}: \mathrm{p}<0.05, * *: \mathrm{p}<0.01, * * *: \mathrm{p}<0.001\right)$.

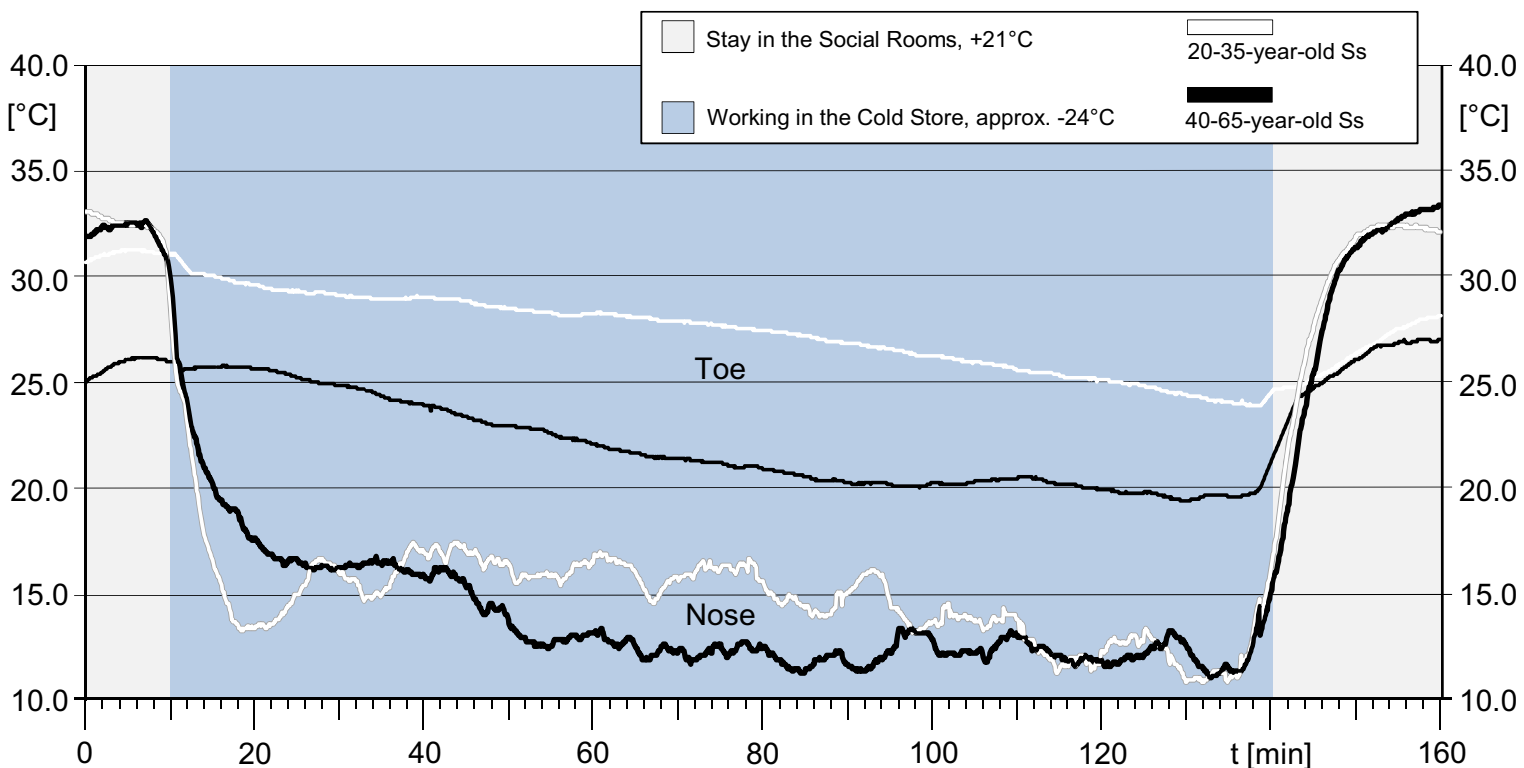

Fig. 4. Means of skin temperature $\left[{ }^{\circ} \mathrm{C}\right]$ at the nose and toe of 15 female Ss in two age groups, each, prior to, during and after a cold exposure of $120 \mathrm{~min}$ at approx. $-24^{\circ} \mathrm{C}$ in the cold store. 


\section{Discussion}

The results of the study show that despite the partly adequate cold protective clothing and the physical strenuous work of manually handling frozen groceries, working in the cold leads to significant decreases of the body core and skin surface temperature. On average the body core temperature of both age groups decreased to $35.6^{\circ} \mathrm{C}$, but there were 7 individuals in the age group of the 40- to 65 -yearolds whose temperature dropped under $35^{\circ} \mathrm{C}$. None of these individuals reached their initial temperature after the 20-minutes warming-up breaks. 3 persons (all of them over 50 years old) showed a temperature drop under $35^{\circ} \mathrm{C}$ in all 3 working phases. Subject number 14 (age: 61 years, height: $1.73 \mathrm{~m}$, body mass: $103 \mathrm{~kg}$ ) exhibited in every working phase substantial decreases of $2.4 \mathrm{~K}$ down to $34.1^{\circ} \mathrm{C}$. According to a German standard [44] a health risk cannot be excluded if the body core temperature drops under $35^{\circ} \mathrm{C}$. Therefore, questions have arisen whether this kind of work is practicable in the long run under today's working conditions in cold-storage depots. It is practicable for the chill room where no values were measured that pose a risk to health. The physiological responses to the cold exposure in the cold store, however, do not meet the requirements of this standard and more attention should be paid to an extension of the warming-up breaks within further surveys.

The skin surface temperature of the toes showed a slight decrease compared to the laboratory tests already mentioned in the introduction. A slight decrease was also determined by Kluth et al. (cp. $[19,20])$, suggesting that the physical activity of order-picking with increased blood circulation has a positive effect of the toes skin surface temperature. However, the skin surface temperature of the fingers and nose decreased very quickly and intensely after exposure to the cold. In individual cases, temperature values lower than $10^{\circ} \mathrm{C}$ were reached. The skin surface temperature of one subject's fingertip fell below $3^{\circ} \mathrm{C}$ within 20 minutes of exposure to the cold. This resulted in severe pain which persisted even after the warming-up break.

Even if the measured physiological responses indicate adequate protection against cold, the described individual cases show that the existing cold protective clothing and the working time in relation with the duration of the warming-up breaks is not sufficient for these persons.

\section{Conclusion}

The structure of the labour market is constantly undergoing change, away from fresh and homegrown towards chilled and frozen food, and its future trend is shown clearly through the development in recent years.

The working population - due to the demographic changes - will become older and even more women will be present in the workforce. In particular physically demanding work, which was a few decades ago only for men, is increasingly performed by women. Therefore, in the future more older female workers partake in physically demanding work under particularly difficult environmental conditions. Due to a decreasing physical capacity and energy metabolism of older humans and in particular women, this led to the assumption that this group must be protected in a special way when working in the cold. The results of this survey in combination with the findings of Kluth et al. (cp. $[19,20])$ however, show, that older females are not in a worse position regarding protection against cold compared to young males. Therefore, it is not necessary to create working conditions adapted on gender and age; rather an optimization should be conducted with the aim of a holistic employment protection. Primarily, this includes the optimization of the mix of working- and break-times as well as the cold protective clothing which do not provide an adequate protection against cold, for an indefinite period and for all body parts. Especially the cold-insulating boots and gloves need some improvements.

\section{References}

[1] J.C. Behrends, J. Bischofberger, R. Deutzmann, H. Ehmke, S. Frings, S. Grissmer, M. Hoth, A. Kurtz, J. Leipziger, F. Müller, C. Pedain, J. Rettig, C. Wagner and E. Wischmeyer, Physiologie, Georg Thieme Verlag, Stuttgart, 2010.

[2] G. Berggren and E. Hohwü Christensen, Heart rate and body temperature as indices of metabolic rate during work, Arbeitsphysiologie 14 (1950), 255-260.

[3] B. Bilger, Untersuchungen an Kopf-, Hand- und Fußbekleidungen zur quantitativen Erfassung der Auswirkung lokaler Wärmeverluste auf das subjektive Komfortempfinden des Menschen in kaltem Umgebungsklima, Schlussbericht zum Forschungsvorhaben AIF-Nr. 8413, Bönnigheim, 1994.

[4] B. Bönnemark, L. Johansson, J. Keiding, H. Magnusson, B. Palmgren and A. Söderqvist, Arbete i fryshus, Rapport A141.69, Arbetsmediciniska Institutet, Stockholm, 1969.

[5] W.M. Boothby, J. Berkson and H.L. Dunn, Studies of the energy metabolism of normal individuals, a standard for basal metabolism, with a nomogram for clinical application, American Journal of Physiology, 116(2) (1936), 468-484.

[6] D. Brajkovic and M.B. Ducharme, Facial cold-induced vasodilation and skin temperature during exposure to cold wind, 
European Journal of Applied Physiology, 96(6) (2006), 711721.

[7] R.E. Clark, The limiting hand skin temperature for unaffected manual performance in the cold, Journal of Applied Psychology, 45(3) (1961), 193-194.

[8] E.R. Dusek, Effect of temperature on manual performance, in: protection and functioning of the hands in cold climates, F.R. Fisher, ed., National Academy of Science - National Research Council, Washington D.C., 1957, pp. 63-76.

[9] J.A. Faulkner, E. Zerba and S.V. Brooks, Muscle temperature of mammals: cooling impairs most functional properties, American Journal of Physiology, 28 (1990), 259-265.

[10] A. Forsthoff, Arbeit in $-28^{\circ} \mathrm{C}$, Arbeitsphysiologische Untersuchung zur klimatischen Belastung bei Körperarbeit in extrem tiefen Umgebungstemperaturen unter besonderer Berücksichtigung der Kühlhausarbeit, Dokumentation Arbeitswissenschaft, Band 9, Otto Schmidt Verlag, Köln, 1983.

[11] W.F. Fox, Human performance in the cold, The Journal of the Human Factors and Ergonomics Society, 9(3) (1967), 203-220.

[12]D. Gavhed, T. Mäkinen, I. Holmér and H. Rintamäki, Face cooling by cold wind in walking subjects, International Journal of Biometeorology, 43(3) (2003), 148-155.

[13]J. Hassi, T. Mäkinen, I. Holmér, A. Påsche and T. Risikko, Handbok för kallt arbete, Arbetslivsinstitutet, Solna, 2002.

[14]J. Hassi, M. Rytkönen, J. Kotaniemi and H. Rintamäki, Impacts of cold climate on human heat balance, performance and health in circumpolar areas, International Journal of Circumpolar Health, 64(5) (2005), 459-467.

[15]B. Hellstrøm, K. Berg and F. Vogt Lorentzen, Human peripheral rewarming during exercise in the cold, Journal of Applied Physiology, 29(2) (1970), 191-199.

[16]R. Imamura, S. Rissanen, M. Kinnunen and H. Rintamäki, Manual performance in cold conditions while wearing NBC clothing, Ergonomics, 41(10) (1998), 1421-1432.

[17]R. Kleinöder, Ergonomische Gestaltung von Kältearbeit bei $30^{\circ} \mathrm{C}$ in Kühl- und Gefrierhäusern, Schriftenreihe der Bundesanstalt für Arbeitsschutz, Forschung, Wirtschaftsverlag NW, Dortmund, 1988.

[18]R. Klinke, H.-C. Pape, A. Kurtz and S. Silbernagl, Physiologie, Georg Thieme Verlag, Stuttgart, 2010.

[19]K. Kluth, M. Penzkofer and H. Strasser, Age-related analysis and assessment of the effects of working in the cold on skin temperature and core temperature of male order-pickers, in: Proceedings of the $2^{\text {nd }}$ International Conference on Applied Human Factors and Ergonomics, Las Vegas, Nevada, USA, 2008.

[20]K. Kluth, M. Penzkofer and H. Strasser, Physiological responses of core and skin temperature of two age groups to working in the cold at $+3{ }^{\circ} \mathrm{C}$ and $-24^{\circ} \mathrm{C}$, Occupational Ergonomics 8(4) (2008/2009), 147-157.

[21]K. Kluth, S. Baldus and H. Strasser, Order-picking in deep cold - physiological responses of younger and older females. Part 1: Heart Rate, in: Proceedings of the $18^{\text {th }}$ World Congress on Ergonomics, Recife, Brazil, 2012.

[22]T.M. Mäkinen, Human cold exposure, adaptation, and performance in high latitude environments, American Journal of Human Biology, 19(2) (2007), 155-164.

[23]R. Morton and K.A. Provins, Finger numbness after acute local exposure to cold, Journal of Applied Physiology, 15(1) (1960), 149-154.

[24]H.W. Müller-Arnecke and U. Hold, Ergonomische Gestaltung von Kältearbeit im Bereich von $0^{\circ} \mathrm{C}$, Schriftenreihe der Bundesanstalt für Arbeitsschutz und Arbeitsmedizin, $\mathrm{Fb} 845$, Wirtschaftsverlag NW, Dortmund, 1999.

[25]M. Nielsen, Die Regulation der Körperkerntemperatur bei Muskelarbeit, Skand. Arch. Physiol., 79 (1938), 193-230.
[26]R. Nielsen and B. Nielsen, Influence of skin temperature distribution on thermal sensation in a cool environment, European Journal of Applied Physiology and Occupational Physiology, 53(3) (1984), 225-230.

[27]J. Oksa, Cooling and neuromuscular performance in man, Ph.D. Thesis, University of Jyväksylä, 1998.

[28]J. Oksa, M.B. Ducharme and H. Rintamäki, Combined effect of repetitive work and cold on muscle function and fatigue, Journal of Applied Physiology, 92(1) (2002), 354-361.

[29]H. Ozaki, H. Enomoto-Koshimizu, Y. Tochihara and K. Nakamura, Thermal responses from repeated exposure to severe cold with intermittent warmer temperatures, 17(5) (1998), 195-205.

[30]L.A. Palinkas, Mental and cognitive performance in the cold, International Journal of Circumpolar Health, 60(3) (2001), 430-439.

[31]J.J. Pilcher, E. Nadler and C. Busch, Effects of hot and cold temperature exposure on performance: a meta-analytic review, Ergonomics, 45(10) (2002), 682-698.

[32]K.A. Provins and R.S. Clarke, The effect of cold on manual performance, Journal of Occupational Medicine, 2 (1960), 169-176.

[33]J.D. Ramsey, C.L. Burford, M.Y. Beshir and R.C. Jensen, Effects of workplace thermal conditions on safe work behaviour, Journal of Safety Research, 14(3) (1983), 105-114.

[34]B. Saltin and L. Hermansen, Esophageal, rectal, and muscle temperature during exercise, Journal of Applied Physiology, 21(6) (1966), 1757-1762.

[35]E. Sormunen, J. Oksa, T. Pienimäki, S. Rissanen and H. Rintamäki, Muscular and cold strain of female workers in meatpacking work, International Journal of Industrial Ergonomics, 36(8) (2006), 713-720.

[36] J.C. Stevens, B.G. Green and A.S. Krimsley, Punctate pressure sensitivity: effects of skin temperature, Sensory Processes, 1(3) (1977), 238-243.

[37]J.M. Stocks, N.A. Taylor, M.J. Tipton and J.E. Greenleaf, Human physiological responses to cold exposure, Aviation, Space, and Environmental Medicine, 75(5) (2004), 444-457.

[38]H. Strasser and K. Kluth, Sensations of cold and physiological responses to groceries handling in cold-storage depots, in: Proceedings of the $16^{\text {th }}$ Triennial Congress of the International Ergonomics Association, 6 pp., Maastricht, The Netherlands, 2006

[39]Y. Tochihara, Work in artificial cold environments, Journal of Physiological Anthropology and Applied Human Science 24(1) (2005), 73-76.

[40]J.H. Veghte and J.I. Clogston, A new heavy winter flying clothing assembly, Alaskan Air Command, Technical Note AAL-Tn-61-4, Archiv Aeromedical Laboratory, Fort Weinwright, 1961.

[41]H.G. Wenzel and C. Piekarski, Klima und Arbeit, Bayerisches Staatsministerium für Arbeit und Sozialordnung, München, 1980

[42]DIN EN ISO 9886, Ergonomics - Evaluation of thermal strain by physiological measurements, Beuth Verlag, Berlin, 2007.

[43]DIN EN ISO 11079, Ergonomics of the thermal environment Determination and interpretation of cold stress when using required clothing insulation (IREQ) and local cooling effects, Beuth Verlag, Berlin, 2007.

[44]DIN 33403, Climate at the workplace and in its environments - Part 2: Effect of the climate on the heat balance of human beings, Beuth Verlag, Berlin, 2000. 